\title{
Dampak Harga Minyak Dunia Terhadap Jumlah Uang Beredar di Indonesia Tahun 2005.Q1-2016.Q4
}

\author{
(The Impact of World Oil Prices on the Money Supply \\ in Indonesia Year 2005.Q1-2016.Q4)
}

\author{
Mita Pradnya Wardani, Regina Niken W.*, Agus Lutfi \\ Jurusan Ilmu Ekonomi dan Studi Pembangunan, Fakultas Ekonomi dan Bisnis, Universitas Jember (UNEJ) \\ Jln. Kalimantan 37, Jember 68121 \\ E-mail: reginanikenw.feb@unej.ac.id
}

\begin{abstract}
Abstrak
Kebijakan yang diambil oleh pemerintah dan bank sentral sangat menentukan besar kecilnya jumlah uang beredar. Harga minyak dunia turut berperan dalam peningkatan jumlah uang beredar melalui inflasi yang terjadi. Tujuan penelitian ini adalah untuk mengetahui kebijakan yang paling efektif dalam mengendalikan jumlah uang beredar oleh masyarakat, dengan menggunakan model Vector Autoregressive (VAR) untuk mengestimasi variabel-variabel didalam penelitian. Estimasi impulse response function dan juga variance decomposition yang menguraikan bagaimana dan seberapa besar pengaruh shock dari jumlah jumlah uang beredar. Estimasi VAR menunjukkan jumlah uang beredar paling signifikan dipengaruhi oleh jumlah uang beredar itu sendiri, pertumbuhan ekonomi, suku bunga deposito dan nilai tukar sedangkan inflasi tidak berpengaruh signifikan terhadap jumlah uang beredar. Analisis impulse response menunjukkan bahwa jumlah uang beredar mendapat respons paling cepat dan paling kuat oleh inflasi. Sedangkan pada uraian variance decomposition, variasi yang dijelaskan jumlah uang beredar besar mempengaruhi perubahan pada jumlah uang beredar itu sendiri dan diurutan kedua adalah pertumbuhan ekonomi.
\end{abstract}

Kata kunci: JUB, Harga Minyak Dunia, Inflasi, Produk Domestik Bruto, Suku Bunga, Kurs.

\begin{abstract}
Policies taken by the government and the central bank greatly determine the size of the money supply. World oil prices play a role in increasing the money supply through inflation. The purpose of this study is to find out the most effective policy in controlling the money supply by the public, using the Vector Autoregressive (VAR) model to estimate the variables in the study. The estimation of the impulse response function and also the variance decomposition which describes how and how much influence the shock from the amount of money supply. The VAR estimation shows that the money supply is most significantly influenced by the money supply itself, economic growth, deposit rates and exchange rates while inflation does not have a significant effect on the money supply. Impulse response analysis shows that the money supply gets the fastest and most powerful response to inflation. Whereas in the description of variance decomposition, the variation explained by the large money supply affects the change in the money supply itself and the second rank is economic growth.
\end{abstract}

Keywords: Oil Prices, Inflation, Gross Domestic Product, Interest Rate, Exchange Rate.

\section{Pendahuluan}

Sebagai negara yang sedang berkembang, Indonesia tidak luput dari berbagai macam permasalahan, terutama pada sektor ekonomi. Kebijakan makroekonomi yang dapat diambil oleh suatu negara untuk menciptakan stabilitas perekonomiannya ada dua, yaitu kebijakan moneter dan kebijakan fiskal. Kedua kebijakan ini saling mendukung dan melengkapi antara satu dengan yang lain dari waktu ke waktu sehingga tercapai sasaran secara efektif. Permintaan uang memegang peranan penting dalam perilaku kebijakan moneter di setiap perekonomian. Banyak literatur yang telah memuat aspek teoritis maupun empiris tentang jumlah uang beredar di negara-negara yang sudah maju maupun negaranegara yang sedang berkembang. Tidak dapat dipungkiri bahwa kebijakan moneter telah banyak mencapai tujuantujuan ekonomi. Friedman berpendapat bahwa kebijakan moneter dapat memberikan kontribusi dalam mencapai stabilitas ekonomi dengan mengendalikan besaran-besaran moneter dalam perekonomian (Sugiyanto, 1995).

Pada era modern uang digunakan sebagai alat pertukaran (medium of exchange), suatu kekayaan riil (tangible asset) yang diterima sebagai alat pembayaran serta penyimpanan nilai (Sukirno,1995). Seringkali permintaan masyarakat akan uang sangat besar sehingga sulit untuk menentukan keseimbangan antara jumlah uang yang diminta dengan jumlah uang yang ditawarkan. Peranan uang dalam suatu perekonomian modern merupakan hal yang sangat penting. Peranan uang sangat penting baik dilihat dari fungsinya atau peranannya dalam meningkatkan efisiensi kegiatan ekonomi masyarakat. Peranan uang sangat ditentukan oleh nilai atau harga uang tersebut relatif terhadap harga komoditi lain. Oleh karena itu juga ditentukan oleh kekuatan permintaan dan penawaran uang (Zainuri, 1996).

Dari sisi kebijakan moneter, tujuan pokok Bank Indonesia (BI) berdasarkan Undang-Undang No. 23 tahun 1999, sebagaimana telah diubah dengan Undang-Undang No. 3 tahun 2004, adalah mencapai dan memelihara kestabilan nilai uang. Kestabilan nilai uang mengandung dua aspek, yaitu kestabilan nilai mata uang rupiah tehadap harga barang dan jasa, serta kestabilan nilai mata uang terhadap mata uang lain. Kestabilan harga dapat diukur dari tingkat inflasi. Kebijakan moneter untuk mengendalikan tingkat inflasi dilakukan dengan cara price targeting dan dengan cara pendekatan kuantitas dalam jumlah uang beredar.

\footnotetext{
* Corresponding author
} 
Dalam mengendalikan tingkat inflasi, maka BI menjaga keseimbangan antara jumlah uang beredar dengan permintaan uang masyarakat. BI menghitung secara akurat untuk menentukan jumlah uang beredar agar tidak terjadi kelebihan suplai yang dapat menyebabkan inflasi yang tinggi daripada yang ditargetkan. Karena itu, BI sebagai otoritas moneter harus dapat menentukan variabel yang harus diukur agar uang beredar sesuai dengan permintaan uang.

Uang lebih cenderung mempengaruhi tinggi rendahnya harga karena semakin banyaknya jumlah uang yang beredar di masyarakat maka akan menyebabkan harga barang menjadi tinggi (Sukirno, 1995). Salah satu faktor yang menyebabkan kenaikan harga barang dan jasa di masyarakat juga di akibatkan karena adanya peningkatan harga minyak dunia. Kenaikan harga minyak dunia tentu saja sangat mempengaruhi kenaikan harga bahan bakar minyak (BBM) di indonesia yang di ikuti meningkatnya harga-harga barang dan jasa secara keseluruhan atau inflasi. Harga minyak mentah yang lebih tinggiakan segera diikuti oleh naiknya hargaproduk-produk minyak, seperti bensindan minyak bakar yang digunakankonsumen (Cologni and Manera,2008).

Menurut Keynes salah satu faktor yang mempengaruhi permintaan uang adalah tingkat suku bunga. Tingkat suku bunga disini adalah tingkat suku bunga deposito, karena dengan adanya hal tersebut bisa menjadi pilihan alternatif bagi masyarakat yang tidak ingin membelanjakan uangnya, sehingga diharapkan dengan adanya tingkat bunga dapat menambah pendapatan dari masyarakat.Perubahan tingkat suku bunga dapat mempengaruhi permintaan uang melalui efek keputusan pada masyarakat. Di Indonesia sendiri tingkat suku bunga cenderung berfluktuatif. Tingkat suku bunga yang tinggi akan menyebabkan masyarakat cenderung menyimpan uangnya dalam bentuk tabungan di bank dari pada memegang uang kas. Hal ini sesuai dengan penelitian yang dilakukan oleh Kumar et .al (2013) yang membuktikan adanya hubungan tingkat suku bunga dengan jumlah permintaan uang yang dilakukan di Nigeria.

Berbagai studi mengenai permintaan uang membuktikan adanya hubungan positif antara GDP dengan jumlah permintaan uang. Hal ini sesuai dengan pernyataan Kumar et. al (2013), PDB berpengaruh terhadap jumlah permintaan uang. Stabilitas permintaan uang dapat diartikan sebagai permintaan uang yang dapat diprediksi oleh otoritas moneter, sehingga jumlah uang beredar yang dikontrol oleh otoritas moneter dapat mempengaruhi variabel-variabel ekonomi lainnya (suku bunga dan PDB) dengan besaran yang dapat diukur (Judd \& Scadding, 1982). Faktor lain yang juga dapat mempengaruhi perintaan uang adalah nilai tukar.

Berdasarkan berbagai penelitian dan teori yang ditunjukkan di atas membuktikan bahwa jumlah uang beredar bersifat tidak konstan, terlebih saat terjadi kenaikan harga minyak dunia. Penelitian ini ditujukan mengetahui pengaruh harga minyak dunia dan variabel makroekonomi yaitu inflasi, GDP, suku bunga, dan nilai tukar di Indonesia. Dikaji dengan beberapa teori permintaan uang. Hipotesis awal penelitian ini adalah 1) Harga minyak dunia berpengaruh positif signifikan terhadap jumlah uang beredar di Indonesia, 2)Inflasi berpengaruh positif signifikan terhadap jumlah uang beredar di Indonesia, 3) Gross Domestic Product (GDP) berpengaruh positif signifikan terhadap jumlah uang beredar di Indonesia, 4) Suku bunga berpengaruh negatif signifikan terhadap jumlah uang beredar di Indonesia, 5) Nilai tukar (kurs) berpengaruh positif signifikan terhadap jumlah uang beredar di Indonesia.

\section{Metode}

\section{Rancangan atau Desain Penelitian}

Tipe hubungan antar variabel yang diteliti dalam penelitian ini adalah hubungan korelasional, horison waktu dalam penelitian merupakan studi time series selama periode waktu tahun 2005.Q1-2016.Q4. Data yang digunakan adalah data sekunder yang diolah menggunakan analisis Vector Auto Regressive (VAR).

\section{Jenis dan Sumber Data}

Jenis data dalam penelitian ini adalah data sekunder. Sumber data diperoleh dari Bank Indonesia, Badan Pusat Statistik (BPS) dan International Monetery Fund (IMF), dan U.S Energy Information Administration (EIA).

\section{Populasi dan Sampel}

Penelitian ini menggunakan populasi Jumlah Uang Beredar, Inflasi, GDP, Suku Bunga dan Nilai Tukar di Indonesia. Sampel yang digunakan yaitu IHK (Indeks Harga Konsumen), M2, tahun 2005.Q1-2016.Q4.

\section{Metode Analisis Data}

Penelitian ini menggunakan pendekatan analisis kuantitatif dengan daerah penelitian adalah Indonesia. Fokus penelitian ini adalah mengetahui hubungan yang saling menyebabkan (kausalitas) terhadap jumlah uang beredar di Indonesia. Sumber data penelitian berasal dari Bank Indonesia dan institusi terkait lainnya. Periode 2005.Q1 sampai 2016.Q4. Tahun 2005 merupakan tahun dimana inflasi mencapat angka tertinggi pada periode penelitian. Metode analisis data yang digunakan adalah vector auto regressive (VAR). Variabel terikat yang digunakan dalam penelitian adalah jumlah uang beredar sedangakan variabel bebas yang digunakan adalah inflasi, GDP, suku bunga, dan nilai tukar.

Model ekonometrika yang digunakan adalah sebagai berikut:

$$
\begin{aligned}
& \mathrm{MDt}=\beta 1+\beta 2 \text { Inft- } 1+\beta 3 \text { IRt-1 }+\beta 4 \text { Yt-1 }+\beta 5 \text { POILt-1 } \\
& + \text { KURSt-1+ e1 } \\
& \mathrm{INFt}=\beta 1+\beta 2 \mathrm{MDt}-1+\beta 3 \text { IRt }-1+\beta 4 \text { Yt }-1+\beta 5 \text { POILt- } 1 \\
& +\mathrm{KURS}+\mathrm{e} 2 \\
& \text { IRt }=\beta 1+\beta 2 \text { MDt }-1+\beta 3 \text { INFt }-1+\beta 4 \text { Yt }-1+\beta 5 \text { POILt }-1 \\
& +\mathrm{KURS}+\mathrm{e} 3 \\
& \mathrm{Yt}=\beta 1+\beta 2 \mathrm{MDt}-1+\beta 3 \text { INFt- } 1+\beta \text { 4IRt }-1+\beta \text { 5POILt }-1 \\
& +\mathrm{KURS}+\mathrm{e} 4 \\
& \text { POILt }=\beta 1+\beta 2 \text { MDt- } 1+\beta 3 \text { INFt- } 1+\beta 4 \text { IRt }-1+\beta 5 \text { Yt }-1 \\
& +\mathrm{KURS}+\mathrm{e} 5 \\
& \text { KURSt }=\beta 1+\beta 2 \text { MDt- } 1+\beta 3 \text { INFt }-1+\beta 4 \text { IRt }-1+\beta 5 \text { Yt }-1 \\
& +\beta 5 \text { POILt-1 }+ \text { e6 } \\
& \mathrm{MD}=\text { Jumlah Uang Beredar (M2) } \\
& \text { INF }=\text { Inflasi } \\
& \text { IR } \quad=\text { Tingkat Suku Bunga } \\
& \mathrm{Y}=\text { Gross Domestic Product } \\
& \text { POIL = Harga Minyak Dunia }
\end{aligned}
$$


Uji asumsi klasik yang digunakan yaitu 1) uji linieritas, 2) uji multikolinieritas, 3) uji autokorelasi, 4) uji heteroskedastisitas, dan 5) uji normalitas.

\section{Hasil dan Pembahasan}

\section{Hasil}

Pengujian data dalam penelitian ini menggunakan analisis kuantitatif dengan metode vector auto regressive (VAR). Penggunaan metode VAR adalah untuk mengetahui hubungan yang saling "menyebabkan" (kausalitas) antara variabel dalam satu sistem dimana semua variabel dalam model bersifat endogen.

\section{Uji Kausalitas Granger (Grager causality test)}

Dalam penelitian ini digunakan uji kausalitas dengan menggunakan model multivariat VAR yang dilakukan secara bersamaan. Setiap variabel dipertukarkan dari variabel endogen menjadi variabel eksogen untuk diuji hubungan kausalitas. Dari perhitungan statistik $\chi 2$ - Wald menunjukkan joint significance dari lag variabel endogen dalam persamaan VAR. Hasil pengujian kausalitas granger pada Tabel 1 sebagai berikut:

\section{Tabel 1: Hasil Uji Kausalitas Granger}

ranger Causality/Block Exogeneity Wald Tests

Date: 07/06/17 Time: 08:26

Sample: 2005Q1 2016Q4

Included observations: 36

\begin{tabular}{cccc}
\hline \multicolumn{3}{l}{ Dependent variable: M2_LN } & \\
\hline Excluded & Chi-sq & df & Prob. \\
\hline POIL & 4.726962 & 3 & 0.1929 \\
INF & 3.001245 & 3 & 0.0914 \\
GDP & 3.082273 & 3 & 0.3791 \\
IR & 4.941023 & 3 & 0.0162 \\
KURS & 7.240164 & 3 & 0.0246 \\
\hline \hline
\end{tabular}

Dependent variable: POIL

\begin{tabular}{cccc}
\hline \hline Excluded & Chi-sq & df & Prob. \\
\hline \hline JUB & 0.419174 & 3 & 0.9363 \\
INF & 4.984537 & 3 & 0.1729 \\
GDP & 1.218209 & 3 & 0.7486 \\
IR & 11.15295 & 3 & 0.0109 \\
KURS & 0.427462 & 3 & 0.9345 \\
\hline \hline All & 24.99808 & 15 & 0.0500 \\
\hline
\end{tabular}

\begin{tabular}{cccc}
\hline \multicolumn{2}{l}{ Dependent variable: INF } & & \\
\hline Excluded & Chi-sq & Df & Prob. \\
\hline \hline JUB & 6.403036 & 3 & 0.0936 \\
POIL & 4.466029 & 3 & 0.2153 \\
GDP & 10.76792 & 3 & 0.0130 \\
IR & 9.560655 & 3 & 0.0227 \\
KURS & 3.277423 & 3 & 0.3508 \\
\hline All & 45.53202 & 15 & 0.0001 \\
\hline
\end{tabular}

Dependent variable: GDP

\begin{tabular}{cccc}
\hline Excluded & Chi-sq & Df & Prob. \\
\hline \hline JUB & 4.860291 & 3 & 0.1823 \\
POIL & 8.005821 & 3 & 0.0459 \\
INF & 8.757540 & 3 & 0.0327 \\
IR & 19.15756 & 3 & 0.0003 \\
KURS & 26.20122 & 3 & 0.0000 \\
\hline All & 51.13993 & 15 & 0.0000 \\
\hline
\end{tabular}

Dependent variable: IR

\begin{tabular}{cccc}
\hline Excluded & Chi-sq & Df & Prob. \\
\hline \hline JUB & 8.295233 & 3 & 0.0403 \\
POIL & 3.821663 & 3 & 0.2814 \\
INF & 2.188225 & 3 & 0.5343 \\
GDP & 1.478800 & 3 & 0.6872 \\
KURS & 5.412154 & 3 & 0.1440 \\
\hline \hline
\end{tabular}

Dependent variable: KURS

\begin{tabular}{cccc}
\hline \hline Excluded & Chi-sq & df & Prob. \\
\hline \hline JUB & 0.377744 & 3 & 0.9448 \\
POIL & 8.905153 & 3 & 0.0306 \\
INF & 9.575372 & 3 & 0.0225 \\
GDP & 2.848646 & 3 & 0.4156 \\
IR & 14.95225 & 3 & 0.0019 \\
\hline All & 44.63215 & 15 & 0.0001 \\
\hline
\end{tabular}

Berdasarkan uji kausalitas granger, tedapat hubungan satu arah antara INF, IR dan KURS terhadap JUB. Hal itu menunjukkan bahwa jumlah uang beredar selain dipengaruhi oleh nilai tukar, juga dipengaruhi oleh kebijakan moneter melalui inflasi dan suku bunga.

Pada variabel harga minyak dunia POIL menunjukkan bahwa terdapat hubungan satu arah antara IR terhadap POIL. Indonesia merupakan salah satu negara pengimpor minyak, meningkatnya harga minyak, akan meningkatkan inflasi sehingga akan mempengaruhi tingkat suku bunga sebagai respon dari kebijakan Bank Indonesia.

Variabel pertumbuhan ekonomi JUB, GDP, IR memiliki hubungan satu arah dengan inflasi. Dimana pertumbuhan ekonomi lebih besar pengaruhnya dalam mempengaruhi inflasi.

Variabel POIL, INF, dan IR mempunyai hubungan satu arah terhadap GDP. Hasil tersebut menunjukkan bahwa variabel JUB, INF, dan IR mempunyai pengaruh terhadap GDP. Kenaikan suku bunga yang dilakukan oleh bank Sentral, maka akan direspon oleh para pelaku pasar dan para penanam modal untuk memanfaatkan moment tersebut guna meningkatkan produksi dan menanamkan investasinya. Seiring dengan itu, akan berdampak juga pada jumlah produksi yang bertambah dan tenaga kerja yang juga akan semakin bertambah. Akibatnya ekspor bertambah dan jumlah pengangguran menurun, sehingga meningkatkan 
pertumbuhan ekonomi. Sedangkan pada variabel Kurs mempunyai hubungan dua arah terhadap GDP.

Variabel JUB mempunyai hubungan satu arah terhadap suku bunga. Hasil tersebut menunjukkan bahwa JUB akan mempengaruhi tingkat bunga, sebagai salah satu instrumen kebijakan moneter dalam menjaga stabilitas ekonomi.

Variabel POIL, INF, dan IR mempunyai hubungan satu arah terhadap nilai tukar. Dengan meningkatnya harga minyak dunia akan menaikkan harga barang sekaligus akan menaikkan nilai tukar mata uang atau kurs.

\section{Estimasi VAR}

Hasil estimasi dengan metode VAR dijelaskan dalam Tabel 2 berikut:

Tabel 2. Hasil Estimasi VAR

\begin{tabular}{|c|c|c|}
\hline & M2 & t-statistik \\
\hline $\mathrm{JUB}(-1)$ & 0.020630 & 0.09077 \\
\hline JUB(-2) & $1.162628 * * *$ & 3.45166 \\
\hline JUB(-3) & 0.209413 & 0.93421 \\
\hline POIL(-1) & $0.107967^{*}$ & 1.72738 \\
\hline POIL(-2) & $-0.124414 *$ & -1.79454 \\
\hline POIL(-3) & 0.002559 & 0.03990 \\
\hline $\operatorname{INF}(-1)$ & -0.005855 & -1.48830 \\
\hline $\operatorname{INF}(-2)$ & 0.002953 & 0.49290 \\
\hline $\operatorname{INF}(-3)$ & 0.001302 & 0.39120 \\
\hline GDP(-1) & 7.001515 & 1.51108 \\
\hline GDP(-2) & -5.414432 & -0.16732 \\
\hline GDP(-3) & $-1.882025^{*}$ & -1.75149 \\
\hline \multirow[t]{2}{*}{$\operatorname{IR}(-1)$} & $0.022334 *$ & 1.97744 \\
\hline & M2 & t-statistik \\
\hline $\operatorname{IR}(-2)$ & -0.014578 & -0.61851 \\
\hline $\operatorname{IR}(-3)$ & -0.001659 & -0.11176 \\
\hline KURS(-1) & $3.372102 *$ & 1.99067 \\
\hline KURS(-2) & $-6.712958 * *$ & -2.53783 \\
\hline KURS(-3) & 1.546386 & 0.05613 \\
\hline $\mathrm{C}$ & -4.304545 & -1.62856 \\
\hline R-squared & 0.998023 & \\
\hline Adj. R-squared & 0.995929 & \\
\hline
\end{tabular}

Sumber : data sekunder, 2016.

$$
\begin{array}{ll}
* \text { signifikan pada } \alpha & =0.10, \\
* * \text { signifikan pada } \alpha & =0.05, \\
* * * \text { signifikansi } \alpha & =0.01
\end{array}
$$

Tabel 2 menunjukkan hasil estimasi data dengan metode VAR menunjukkan bahwa JUB berpengaruhg signifikan terhadap jumlah uang beredar. Harga minyak dunia berpengaruh signifikan terhadap jumlah uang beredar. Inflasi tidak signifikan dalam mempengaruhi JUB. Pertumbuhan ekonomi dan kurs signifikan terhadap jumlah uang beredar di Indonesia.

\section{Pembahasan}

Hasil analisis VAR, Perkembangan jumlah uang beredar (JUB) pada tahun 2005 - 2016 menunjukkan pola yang meningkat seiring berjalannya waktu. Dari hasil analisis VAR, naiknya harga minyak dunia berpengaruh signifikan dan positif pada periode pertama terhadap jumlah uang beredar pada (Tabel 2). kenaikan harga minyak akan menyebabkan inflasi yang artinya, proses transmisi dampak kenaikan harga minyak internasional terhadap kenaikan inflasi akan berdampak pada kenaikan jumlah uang beredar. Pengaruh shock harga minyak yang berlangsung ini dapat dipahami terutama karena peranan (bobot) harga bahan bakar minyak (BBM) yang sangat dipengaruhi oleh harga minyak internasional yang cukup besar dalam pembentukan inflasi di dalam negeri. Dampak inflasi karena fluktuasi harga minyak ini akan lebih besar apabila memperhitungkan pengaruhnya yang bersifat tidak langsung (second round effect), seperti melalui kenaikan biaya produksi bagi industri pengguna minyak bumi Sebagai input produksi yang kemudian bermuara pada kenaikan harga barang-barang di tingkat konsumen. Saluran lain adalah melalui anggaran pendapatan dan belanja negara (APBN). Apabila kenaikan harga minyak internasional menyebabkan bertambahnya beban subsidi yang ditanggung APBN dan kemudian direspon oleh pemerintah dengan menaikkan harga BBM bersubsidi, maka desakan inflasi tidak bisa dihindari.

Pada kondisi tersebut, pengaruh shock harga minyak terhadap peningkatan jumlah uang beredar baru akan terlihat. Artinya, kenaikan harga minyak internasional pada akan meningkatkan jumlah uang beredar di dalam negeri. Peningkatan jumlah uang beredar akibat kenaikan harga minyak (real balance effect) direspon dengan segera (cepat) pula oleh otoritas moneter dengan menambah jumlah uang beredar hal ini sesuai dengan penelitian yang di lakukan oleh Wilantari dan Maria (2015) yang menyatakan bahwa meningkatnya harga minyak dunia juga dapat mempengaruhi peningkatan inflasi.

Dari hasil analisis VAR, pada periode pertama hingga periode ke tiga inflasi tidak berpengaruh signifikan terhadap jumlah uang beredar pada (Tabel 2). Artinya naik turunnya inflasi tidak mempunyai pengaruh pada JUB, karena dalam penelitian ini variabel yang digunakan adalah $\mathrm{M} 2$, sehingga apabila terjadi kenaikan ataupun penurunan inflasi lebih berpengaruh pada M1. Pada saat penelitian M2 juga tidak hanya di pengaruhi oleh tingkat inflasi, namun juga dipengaruhi oleh tabungan, deposito, obligasi, dan investasi. Hasil ini tidak sesuai dengan teori dan hipotesis awal, namun selaras dengan penelitian yang dilakukan oleh Kumar et. al (2013) di Nigeria.

Kenaikan inflasi pada periode penelitian yang tertinggi terjadi pada tahun 2005 yang diakibatkan oleh krisis energi dunia yang ditandai dengan naiknya harga minyak dunia menjadi sebuah krisis energi untuk Indonesia. Dimulai tahun 2005 dimana akibat kenaikan harga minyak dunia membuat pemerintah Indonesia menaikkan harga bahan bakar minyak (BBM) meskipun sudah ada subsidi dari pemerintah, tetap mengakibatkan kenaikan harga secara umum. Perilaku kenaikan harga barang-barang kebutuhan masyarakat setelah terjadi kenaikan harga BBM seperti premium (bensin pompa), solar, dan minyak tanah dari waktu ke waktu relatif sama. Misalnya, dengan naiknya premium sebagai bahan bakar transportasi akan menyebabkan naiknya tarif angkutan. Dengan kenaikan tarif angkutan tersebut maka akan mendorong kenaikan harga barang-barang yang banyak 
menggunakan jasa transportasi tersebut dalam distribusi barangnya ke pasar. Demikian pula dengan harga solar yang mengalami kenaikan juga akan menyebabkan kenaikan harga barang atau jasa yang dalam proses produksinya menggunakan solar sebagai sumber energinya.

Hasil estimasi dalam penelitian ini menunjukkan bahwa, meningkatnya pertumbuhan ekonomi pada periode ke-satu mempunyai arah koefisien yang negatif dan berpengaruh tidak signifikan dalam mempengaruhi permintaan uang di Indonesia pada (Tabel 2). Hal ini sesuai dengan teori Baumol bahwa orang menerima pendapatan sejumlah tertentu secara reguler setiap waktu (misalnya setiap awal bulan) serta selalu membelanjakan atau menggunakan penghasilan tersebut untuk tujuan transaksi sejumlah tertentu (tetap) setiap harinya. Dengan kata lain, kebutuhan dana (uang tunai) per satuan waktu adalah konstan. Hal ini sesuai dengan penelitian yang dilakukan oleh Hayati (2006), Setiadi (2013), dan Asghar (2012) di Pakistan yang mengatakan bahwa pendapat tidak selalu digunakan untuk belanja bisa saja di pergunakan untuk transaksi lainnya contohnya saving, oligasi, investasi dan asuransi.

Pertumbuhan ekonomi pada periode penelitian cenderung mengalami kenaikan yang cukup pesat, Perekonomian Indonesia menunjukkan kinerja yang membaik dan lebih stabil selama 2005 sebagaimana yang tercermin pada pertumbuhan ekonomi yang meningkat. Walaupun demikian, pertumbuhan ekonomi yang terjadi masih belum memadai untuk menyerap tambahan angkatan kerja sehingga jumlah pengangguran masih mengalami kenaikan. Aktivitas perdagangan dunia yang masih lesu mengakibatkan pertumbuhan volume ekspor Indonesia, khususnya komoditas nonmigas, relatif rendah. Dalam situasi demikian, kinerja ekspor secara nominal sangat terbantu oleh meningkatnya harga komoditas migas dan nonmigas di pasar internasional, sehingga secara keseluruhan nilai ekspor pada 2005 masih mengalami kenaikan yang signifikan dan menjadi penopang utama terjadinya surplus transaksi berjalan selama 2005. (Laporan Bank Indonesia, 2005)

Hasil estimasi VAR pada (Tabel 2) juga menunjukkan pertumbuhan ekonomi juga mempunyai arah koefisien yang negatif dan berpengaruh signifikan dalam mempengaruhi jumlah uang beredar di Indonesia. Artinya peningkatan pertumbuhan ekonomi akan menyebabkan penurunan jumlah uang beredar karena apabila terjadi peningkatan pertumbuhan ekonomi mengakibatkan peningkatan inflasi akibat dari minat belanja masyarakat yang meningkat karena tingkat pendapatan meningkat sehingga sebagai respon kebijakan dari Bank Indonesia tingkat suku bunga di naikkan yang mempengaruhi keputusan individu terhadap pilihan membelanjakan uang lebih banyak atau menyimpan uangnya dalam bentuk tabungan. Oleh karena itu, pada saat terjadi peningkatan pertumbuhan ekonomi akan mempengaruhi penurunan jumlah uang beredar (JUB) hasil ini sesuai dengan penelitian yang dilakukan oleh Azim et.al (2010) di Pakistan. Namun tidak sesuai dengan hipotesis awal dan teori yang dikemukakan Kaum Klasik (Teori Kuantitas Uang), bahwa permintaan uang dipengaruhi secara positif oleh pendapatan. Salah satu tokohnya adalah Fisher, yang mengatakan bahwa permintaan uang merupakan kepentingan yang sangat likuid untuk memenuhi motif transaksi. Karena itu, pendapatan merupakan faktor yang berpengaruh dalam permintaan uang untuk motif transaksi. Selain Teori Klasik, hasil tersebut juga sesuai dengan teori yang dikemukakan oleh Keynes tentang motif memegang uang yaitu motif transaksi dan berjaga-jaga yang ditentukan oleh tingkat pendapatan, pada saat pendapatan tinggi lebih banyak uang yang diminta untuk tujuan transaksi dan berjaga-jaga, sehingga pada saat pendapatan naik akan menyebabkan peningkatan jumlah uang beredar.

Dari hasil analisis VAR pada Tabel 2, pada periode pertama pertumbuhan ekonomi mempunyai arah koefisien yang positif dan signifikan. Hasil impulse response menunjukan bahwa suku bunga merespons positif secara akumulatif. Hal tersebut menandakan kenaikan suku bunga deposito di respon secara positif oleh masyarakat. Artinya bahwa jika terjadi peningkatan suku bunga maka akan di ikuti dengan peningkatan jumlah uang beredar dalam arti luas (M2). Suku bunga mempengaruhi keputusan individu terhadap pilihan membelanjakan uang lebih banyak atau menyimpan uangnya dalam bentuk tabungan. Untuk menjaga kestabilan nilai mata uang, Bank Indonesia sebagai otoritas moneter diberikan beberapa wewenang dalam melakukan tugasnya. Dengan merumuskan dan melaksanakan kebijakan moneter untuk mengendalikan uang beredar dan suku bunga dalam perekonomian agar dapat mendukung pencapaian tujuan kestabilan nilai uang tidak boleh dilakukan secara fleksibel. Hal ini sesuai dengan penelitian yang dilakukan oleh Kumar et. al (2013).

Dari hasil analisis VAR, meningkatnya tingkat suku bunga pada periode ke dua menunjukkan hasil yang tidak signifikan. Artinya naik turunnya tingkat suku bunga deposito tidak berpengaruh terhadap jumlah uang beredar dalam arti luas (M2). Hal ini dapat di karenakan oleh tingkat suku bunga deposito di Indonesia tidak hanya digunakan untuk mengandalikan jumlah permintaan uang, tingkat suku bunga deposito juga di gunakan Bank Indonesia untuk mengendalikan tingkat inflasi, kredit, dan investasi. Hasil penelitian ini selaras dengan penelitian yang dilakukan oleh Peunescue (2002) yang menyatakan bahwa suku bunga tidak signifikan mempengaruhi permintaan uang di Rumania, karena tingkat suku bunga deposito di tentukan oleh masingmasing bank umum meskipun yang di gunakan adalah suku bunga acuannya satu.

Hasil estimasi VAR nilai tukar terhadap jumlah uang beredar (M2) dalam penelitian ini menunjukkan hasil yang signifikan dan mempunyai arah koefisien yang positif pada periode kesatu dan periode ke-tiga. Artinya peningkatan nilai tukar akan mengakibatkan peningkatan jumlah permintaan uang di Indonesia. Tahun 2005 nilai tukar rupiah mencapai angka Rp9.036/USD menguat jika di bandingkan dengan tahun 2004 yaitu sebesar Rp 9.311/USD. Perubahan nilai tukar dapat berpengaruh terhadap permintaan uang melalui inflasi.

\section{Simpulan}

Berdasar pada analisis yang diuraikan bab sebelumnya, maka kesimpulan secara lebih jelas diterangkan sebagai berikut :

1. Harga minyak dunia berpengaruh positif dan signifikan terhadap jumlah uang beredar di Indonesia.

2. Inflasi berpengaruh negatif dan tidak signifikan terhadap jumlah uang beredar di Indonesia. Hal ini mengindikasikan bahwa pergerakan inflasi tidak memiliki pengaruh terhadap 
tingkat jumlah uang beredar di Indonesia. Hal ini tidak sesuai dengan teori yang ada.

3. GDP berpengaruh positif dan signifikan terhadap jumlah uang beredar di Indonesia. Hal ini mengindikasikan bahwa pergerakan GDP memiliki pengaruh terhadap jumlah uang di Indonesia. Hal ini sesuai dengan teori yang ada.

4. Suku bunga berpengaruh negatif dan signifikan terhadap jumlah uang beredar di Indonesia. Hal ini mengindikasikan bahwa bahwa penurunan suku bunga berpengaruh terhadap peningkatan jumlah uang beredar di Indonesia. Hasil tersebut sesuai dengan teori.

Nilai tukar berpengaruh positif dan signifikan terhadap jumlah uang beredar di Indonesia. Hasil ini mengindikasikan bahwa pergerakan nilai tukar memiliki pengaruh terhadap tingkat inflasi di Indonesia. Hal ini telah sesuai dengan teori.

\section{Referensi}

Azim, P., et. al. 2010. Demand for money in Pakistan: an Ardle Approach. Global Journal of Management and Business Research, Vol. 10.No,5.

Bashier, A dan Dahlan., A. 2011. The money demand function for Jordan: An empirical investigation. International Journal of Business and Social Science.

Budisantoso Totok, Triandaru Sigit. 2009. Bank dan Lembaga Keuangan Lain. Jakarta : Salemba Empat.

Catur, Sugiyanto. 1994. Penyesuaian Nominal dan Penyesuaian Riil Permintaan Uangdi Indonesia, Jurnal Ekonomi dan Bisnis Indonesia No. 1 Tahun VII 1993.
Cologni, A., and Manera. 2008. Oil Prices, Inflation and Interest Rates in a Structural Cointegrated VAR Model for the G-7 Countries.

Hayati, B. 2006. Analisis Stabilitas Permintaan Uang dan Stabilitas Harga Di Indonesia Tahun 1989 - 2002. Semarang: Universitas Diponegoro.

Judd, John P., and John L. Scadding. 1982. The Search For a Stable Money Demand Function: Survey of the post -1973 Literature, Jurnal of economic Literature. Vol, 20. No, 3.

Paunescu, A. 2002. Determinants of Demand for Money in Romania. Bucharest.

Setiadi, I O. 2013. Analisis faktor-faktor yang mempengaruhi permintaan uang di Indonesia tahun 1999: Q1-2010: Q4 dengan pendekatan Error Correction Models (ECM). Economics Development Analysis Journal Vol.2. No. 1.

Sukirno, S. 1995. Pengantar teori ekonomi makro: edisi kedua. Jakarta: PT Raja GrafindoPersada.

Sukirno, S, 1996. Pengantar Teori Makroekonomi: edisi kedua.Jakarta: PT. RajaGrafindoPersada.

Sukirno, S. 2000. Makroekonorni Modern Perkembangan Pemikiran dari Klasik Hingga Keynesian Baru. Jakarta: PT. Raja Grafindo Persada.

Tambunan, T. 2001. Perekonomian Indonesia: Teori dan Temuan Empiris. Jakarta: Ghalia Indonesia.

Wilantari, RN dan Maria, S, W. 2015, Dampak Perubahan Harga Minyak Dunia Terhadap Ekonomi Makro Indonesia, Proceding The $8^{\text {th }}$ NCFB, FEB UKWM

Zainuri. 1996. Pengujian elastisitas harga pada permintaan uang di Indonesia. Majalah Ekonomi, Tahun XXII, No. 2.

Internet:

Bank Indonesia. 2016. Statistik Data. http://www.bi.go.id. 